time this recommendation should apply to salvarsan, since there can be no controversy over the relative merits of the two drugs.

Finally, so far as our own investigations are concerned, we must admit that Dr. Smith is correct in the tentative conclusion contained in his final paragraph. We think that it is essential to apply treatment at once without waiting for the Wassermann reaction; firstly, for the reason that valutreatment will not affect the result of the reaction within any reasonable number of days. It should be applied after treatment has begun. The great merit of the test is not only that it greatly assists in an accurate diagnosis and is almost essential to a prognosis, but it establishes the nature of a case conclusively, although there might be no suspicion of syphilis, and thus permits of a much more thorough treatment than would be applied if the case were left in obscurity. We are, Sir, yours faithfully

JAMES MCINTOSH,

London Hospita], Oct. 13th, 1913

PAUL Filines.

\section{THE MEDICAL MISSIONS OF THE SOCIETY FOR THE PROPAGATION OF THE}

$$
\text { GOSPEL. }
$$

\section{To the Editor of THE LANCET.}

SiR,-I wish to make known some openings for junior members of the medical profession which, putting aside other aspects of the work, provide a variety of cases and scope for the performance of important operations greater than commonly fall to the lot of general practitioners in this country. In the majority of these places there can be also the inspiring reflection that there is no other qualified doctor within many miles to whom the patients could pcssibly apply for the treatment they need. 'The salaries, except in the case of Rusapi in Mashonaland, where there is a Government guarantee of $£ 300$, besides private practice, are small, but sufficient for comfortable maintenance of unmarried doctors, being the same both for men and women as those offered to the clergy working under similar conditions on the S.P.G. Missions in connexion with which these posts are.

The doctors must be in full sympathy with mission work, but will not be required to do any but their professional work, unless they desire it themselves. The vacancies are: for men (1) Hazaribagh, Behar, India ; (2) Rusapi, Mashonaland ; (3) Kwamagwaza, Zululand; for women, (1) Ping Yin, North China ; (2) Delhi, India; (3) Malacca. In all these places the hospitals are in full working order. Several more men are wanted for China and three women for India, but we cannot send them at present owing to lack of funds. Our men never enter into competition with private practitioners or with those working in Government posts. We appeal to members of the medical profession who are in sympathy with the efforts which the Society for the Propagation of the Gospel is now making to meet the great need for medical aid in places otherwise unprovided for, to help us by bringing these vacancies to the notice of some who seem suited to fill them. I shall be glad to answer fully any inquiries made from me about these posts and the needs and plans of this department of the S.P.G.

K. W. S. KENNEDY, M.B.

Westminster, Oct. 14th, 1913 . able time must not be wasted, and secondly, because the

results of the treatment of the "floner of the young intellect" of this country. He does not touch upon the public aspect of the present system of training, in particular with its relation to clinical medicine. Students and teachers alike receive their clinical training from observations upon the "submerged tenth." Now, 50 per cent. of the passed men will enter general practice and try to be useful to the respectable working and middle classes, from whom alone it is possible to expect a living wage. It is obvious that the "system" places upon the community a mass of men clinically un. trained for the duties they have to perform.

The most serious and tangible indictment of the "system" is the mass of literature we (one and all) daily receive relative to proprietary drugs and methods of treatment of disease. All the literature comes from commercial people outside the profession who would not send it and incur great expense unless there were an adequate return. I often wonder how the profession as a whole can tolerate this daily insult. It does not redound to the credit either of teachers or examiners, and emphatically not to the Council for Medical Education.

The desire to see professional training of such a nature as to make the profession a part of each man who practises it is my apology for trespassing upon your space. I am, Sir, yours faithfully,

Manchester, Oct. 13th, 1913. R. Crawshaw Holt.

\section{THE BOUNDARY LINE.}

To the Editor of THE LANCET.

SiR,-May I ask you to publish an objection to a custom which appears to be growing in some quarters of the profession? I refer to a habit which a class of consultant indulges in, of sending broadcast to general practitioners copies of lectures which he has given upon medical subjects. When I receive from a consultant with whom I have had professional relations a paper of his $I$ value it and read it with attention, but when I receive a pamphlet from a gentleman whom I do not know I regard it as a tradesman's circular and treat it as such.

To-day I have received yet another of these, with, in addition, a slip informing me that the writer is "specially interested" in certain disorders, and would be glad to have details of cases from me. I do not know the author, I have never heard of him, and therefore he may be, for anything I can tell to the contrary, a master of his specialty, but as I am never likely to feel myself desirous of testing the point by inviting him in consultation, I am not sufficiently interested in his achievements to undergo the fatigue of reading about them.

of course, he may have included my name in the list of those to be favoured with his pamphlet by error. Yet these errors are of such frequent occurrence that although I am eager to believe such explanations, for the dignity of the profession, yet I have had, very often, great difficulty in doing so. Indeed, if the custom continues I shall find myself forced to regard it as nothing more than a vulgar device for advertising the authors. I hope these gentlemen will not drive me and my fellow practitioners to this extremity. I enclose the "trade circular" in question.

I am, Sir, yours faithfully,

$$
\text { C. Willett Cunnington. }
$$

Church End, Finchley, N., Oct. 11th, 1913.

\section{AN INVESTIGATION INTO INDUSTRIAL
INSURANCE. \\ AN INVESTIGATION INTO INDUSTRIAL
INSURANCE. \\ To the Editor of THE LANCET. \\ To the Editor of THE LANCET.}

SIR,-With your permission I should like to express my grateful thanks to Sir William Osler for his address at the St. George's Hospital Medical School and humbly to express my opinion that it is one of the finest of the many services which he has rendered to the profession.

I am sure that from his pronounced intention of improving the profession he will not object to some of his statements being supplemented by an opinion which is held by many that the "passed" men are, metaphorically speaking. mentally and professionally dead for some time after their success. Some recover their old brilliance, but a very large percentage is permanently damaged by the training.

The rejected men must of necessity go to swell the ranks of the " unemployables."

This opinion is not a whit too severe when we consider the
SIR,-The Fabian Research Department, in compliance with numerous requests, has started a detailed investigation of the various forms of industrial insurance, beginning with the working of the National Health Insurance Act. The investigation will have for its sole purpose to discover what actually is the effect of the Act, and in what way its operation can be improved. Will you permit me to invite insured persons, doctors, nurses, nembers of Insurance Committees, and workers in any way connected with Friendly Societiessuch as sick visitors, agents, secretaries, branch secretaries, \&c. - to contribute facts or other information which they think

We should, for example, be very pleased to receive copies of the minutes and regulations of Insurance Committees; would be of service? 